\title{
Total Mercury Concentration of Wild Caught Fish Purchased from Grocery Stores: A Potential Public Health Concern
}

Miguel A. Aristu* and Taylor J. Pollak*

Environmental Metrology \& Policy, Graduate School of Arts \& Sciences, Georgetown University, 3700 O Street N.W., Washington, DC 20057, United States 
1 ABSTRACT: Methylmercury is a highly toxic organic compound that bioaccumulates and

2 biomagnifies in the human body when absorbed by the gastrointestinal tract after ingestion. ${ }^{1}$ Thus,

3 monitoring methylmercury levels in fish is crucial for protecting public health and preventing

4 dramatic scenarios such as the Minamata disease crisis in Japan. In this study, three different

5 species of wild caught fish - Sockeye Salmon (Oncorhynchus nerka) from Alaska, USA; tuna

6 imported from Vietnam; and swordfish (Xiphias gladius) imported from Indonesia - were

7 collected from a Harris Teeter grocery store in Washington D.C. Total mercury concentration was

8 measured by ICP-MS and the analyzed samples' concentrations were $19.8 \pm 2.9 \mathrm{ppb}, 2.67 \pm 0.01$

9 ppm, and $380 \pm 9$ ppb for Sockeye Salmon, swordfish, and tuna, respectively.

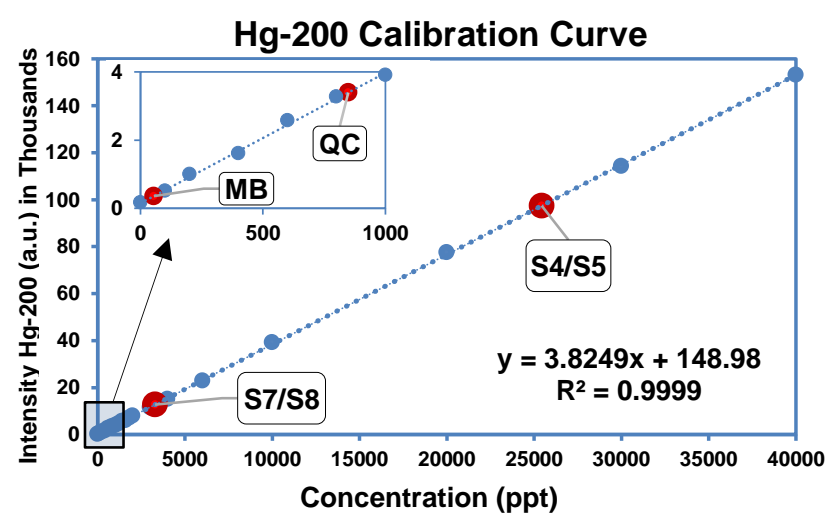

10 KEYWORDS: Methylmercury, tuna, salmon, swordfish, ICP-MS, FDA, environmental

11 pollution, environmental monitoring, action level, import, Indonesia, and Vietnam.

12 SYNOPSIS: Consumption of swordfish is likely to pose a public health risk, as its total mercury

13 concentration (ppm wet-weight) is close to three times higher than the Food and Drug

14 Administration's action level. 


\section{INTRODUCTION}

16 Fish are widely considered a healthy, low-fat source of high quality dietary protein, calcium,

17 phosphorus, and minerals, such as iron, zinc, iodine, magnesium and potassium. ${ }^{2}$ Due to low

18 cholesterol and high omega-3 fatty acids levels, several studies show that long-term fish

19 consumption reduces risk of coronary heart disease, decreases mild hypertension and incidence of

20 diabetes, prevents cardiac arrhythmias, alleviates chronic inflammatory conditions like rheumatoid

21 arthritis, and stimulates the immune system..$^{2-5}$ Indeed, health organizations such as the American

22 Heart Association and the United Kingdom's National Health Service recommend that a healthy

23 diet must contain at least two portions of fish per week. ${ }^{6,7}$ Nevertheless, fish consumption has also

24 been found to be a source of various toxins, mercury being the greatest concern. Thus, monitoring

25 mercury levels in fish is crucial to raise awareness and help people balance the relative benefits

26 and drawbacks of fish consumption. ${ }^{2}$

27 Mercury $(\mathrm{Hg})$ is a heavy metal that, when released into the environment, bioaccumulates and

28 biomagnifies in living organisms as methylmercury $(\mathrm{MeHg})^{1}$, which is highly toxic to the central

29 nervous system. Particularly, exposure to $\mathrm{MeHg}$ among pregnant women leads to increased risk

30 of deformities and cognitive dysfunction of newborn babies, known as the Minamata disease. ${ }^{8}$ In

31 addition, the positive relationship between fish size and $\mathrm{Hg}$ (bioaccumulation) puts consumers who

32 eat larger fish at higher risk of $\mathrm{Hg}$ exposure than those who eat smaller fish. ${ }^{2}$ In this context, we

33 aim to evaluate consumer exposure to $\mathrm{Hg}$ as a function of fish size, species, and region of origin.

34 Results from this study will be of value to those involved in risk communication and public health

35 protection, as well as to provide consumers with the scientific evidence needed to make informed

36 decisions about eating fish. 
The present study is aimed at quantifying total $\mathrm{Hg}$ (CAS No. 7439-97-6) levels for three different

38 species of wild caught fish - Sockeye Salmon from Alaska, USA; tuna imported from Vietnam;

39 and swordfish imported from Indonesia - that were purchased from a Harris Teeter grocery store

40 in Washington D.C. Total Hg concentration was measured using an Inductively Coupled Plasma

41 Mass Spectrometry (ICP-MS) analytical method derived from the Association of Official

42 Agricultural Chemists (AOAC) Official Method 2015.01 for Heavy Metals in Food ${ }^{9}$ and EPA

43 Method 6020B (SW-846): ICP-MS for Heavy Metals in Digests. ${ }^{10}$ Both reference methods are

44 suitable for the characterization of total $\mathrm{Hg}$ at trace levels in food samples. Since $\mathrm{Hg}$

45 bioaccumulates mainly $(\approx 100 \%)$ in the form of $\mathrm{MeHg}\left[\mathrm{CH}_{3} \mathrm{Hg}\right]^{+}$, all organic $\mathrm{Hg}$ will be

46 transformed to inorganic $\mathrm{Hg}\left(\mathrm{Hg}^{2+}\right)$ by using acid digestion. ${ }^{11}$

\section{MATERIALS AND METHODS}

48 Chemicals and Materials

49 Three certified reference materials suitable for ICP trace analysis were provided by Sigma-

50 Aldrich for $(1,000 \pm 2) \mathrm{mg} / \mathrm{L}$ mercury in $12 \% \mathrm{HNO}_{3},(1,000 \pm 2) \mathrm{mg} / \mathrm{L}$ indium in $2 \% \mathrm{HNO}_{3}$, and

$51(1,000 \pm 2) \mathrm{mg} / \mathrm{L}$ gold in $5 \% \mathrm{HCl}$. These certified reference materials are traceable to the SI unit

52 of mass, the kilogram. All working solutions, calibration standards, and samples were acidified to

53 a final concentration of $2 \% \mathrm{w} / \mathrm{w} \mathrm{HNO}_{3}$ to facilitate sample ionization and intensify the signal

54 obtained by the ICP-MS instrument.

\section{Preparation of the Mercury-Stabilizing $A u^{3+}$ Solution}

56 A $100 \mathrm{ppm}$ gold $\left(\mathrm{Au}^{3+}\right)$ working solution was prepared by dilution of the $\mathrm{Au}^{3+}$ primary standard

57 in $2 \% \mathrm{w} / \mathrm{w} \mathrm{HNO}_{3}$. Mercury is relatively volatile at room temperature and extremely volatile when

58 heated. In addition, $\mathrm{Hg}^{2+}$ shows a strong memory effect and may remain in the measurement

59 system even after reasonable rinse times. For this reason, a final $\mathrm{Au}^{3+}$ concentration of 5 ppm was 
60 used in all calibration standards, blanks, and samples as a mercury-stabilizing agent to minimize

61 memory effects, $\mathrm{Hg}^{2+}$ loss throughout the digestion process, and prevent $\mathrm{Hg}^{2+}$ from plating out in

62 the sample introduction system. ${ }^{9,10,12}$ Although some authors reported that a final $\mathrm{Au}^{3+}$

63 concentration of 2 ppm ensures mercury stabilization, stability studies showed that for this method

64 a final $\mathrm{Au}^{3+}$ concentration of 5 ppm was needed to avoid $\mathrm{Hg}^{2+}$ loss. ${ }^{12}$

65 Preparation of the $1 \mathrm{ppb} \mathrm{In}^{3+}$ Internal Standard Solution

66 For the indium internal standard (IS), an intermediate $1 \mathrm{ppm}$ solution and a final $1 \mathrm{ppb}$ working

67 solution were prepared in $2 \% \mathrm{w} / \mathrm{w} \mathrm{HNO}_{3}$. The IS is used for validation of the analytical method

68 and is added into the ICP-MS system separately through a second channel of the peristaltic pump

69 so that the concentration (1 ppb) is consistent for all samples and standards measured. This way,

70 experimental errors arising from pipetting aliquots of IS into the standards and samples are

71 avoided. Indium isotopes measured were ${ }^{115} \operatorname{In}$ and ${ }^{113} \operatorname{In} .{ }^{9,10}$

72 Preparation of the $\mathrm{Hg}^{2+}$ Calibration Curve

73 For the analyte $\left(\mathrm{Hg}^{2+}\right)$, two working solutions - $10 \mathrm{ppm}$ (D1) and $100 \mathrm{ppb}$ (D2) - were prepared

74 in $2 \% \mathrm{w} / \mathrm{w} \mathrm{HNO}_{3}$. A 20-point $\mathrm{Hg}^{2+}$ calibration curve ranging from $100 \mathrm{ppt}$ to $40 \mathrm{ppb}$ was prepared

75 by dilution of $\mathrm{Hg}^{2+}$ working solutions $\mathrm{D} 1$ and $\mathrm{D} 2$ to a final volume of $15 \mathrm{~mL} 2 \% \mathrm{w} / \mathrm{w} \mathrm{HNO}_{3}$. Then,

$76750 \mu \mathrm{L}$ of $\mathrm{Au}^{3+} 100 \mathrm{ppm}$ were added to all standards for a final concentration of $5 \mathrm{ppm}$. For safety

77 reasons, samples were prepared under a fume hood with thick chemical-resistant nitrile gloves.

78 Three types of blanks were prepared, calibration blank, method blank, and rinse blank. The

79 calibration blank was prepared by acidifying water using the same combination and concentrations

80 of acids used in the preparation of the matrix-matched calibration standards, $2 \% \mathrm{HNO}_{3}$ and $5 \mathrm{ppm}$

$81 \mathrm{of} \mathrm{Au}^{3+}$. Calibration blanks help determine signals produced at the detector that do not arise from

82 the presence of the intentionally added analyte to the calibration standards. Method blanks contain 
83 neither the analyte nor the sample but are prepared following all steps of the sample preparation

84 procedure (digestion, dilution, filtering, etc.) and are used to monitor potential contamination

85 resulting from the sample preparation procedure. ${ }^{6}$ The rinse blank is used to flush the system

86 between all samples and standards, and it was prepared as a $2 \% \mathrm{HNO}_{3}$ solution. ${ }^{10}$

87 Sampling and Preparation of Fish Muscle Samples

88 Three different fish species - Sockeye Salmon from Alaska, USA; tuna imported from Vietnam,

89 and swordfish imported from Indonesia - that were advertised as wild caught were collected from

90 a Harris Teeter Super Market at 1631 Kalorama Rd NW, Washington, DC, 20009. After

91 homogenization in a blender, each specimen yielded three samples $(n=9)$. For each species, one

92 sample was spiked with known concentrations of $\mathrm{Hg}^{2+}$ to calculate recoveries. AOAC Official

93 Method 2015.01 for Heavy Metals in Food was followed using a Multiwave Go Plus microwave-

94 assisted digestion system provided by Anton Paar, in order to digest the fish muscle samples. ${ }^{9}$

95 First, the edible portion was blended and homogenized and approximately $1.0 \mathrm{~g}$ wet weight (wet

96 wt) were placed into microwave digestion vessels. Then, $6 \mathrm{~mL}$ of $70 \% \mathrm{HNO}_{3} \mathrm{ICP}$-grade and $2 \mathrm{~mL}$

97 of distilled water (DI $\mathrm{H}_{2} \mathrm{O}$ ) were added into each vessel. Finally, $320 \mu \mathrm{L}$ of the $100 \mathrm{ppm} \mathrm{Au}^{3+}$

98 working solution were added to achieve a final gold concentration of $5 \mathrm{ppm}$ in each sample. One

99 method blank and one $\mathrm{Hg}^{2+}$ spiked sample for each species were prepared per batch of samples

100 digested. Samples were spiked with varying amounts of $\mathrm{Hg}^{2+}$ to account for different $\mathrm{Hg}$

101 concentrations expected for each species after exploratory tests were conducted. Thus, salmon,

102 tuna, and swordfish samples were spiked with a final concentration of $2 \mathrm{ppb}, 35 \mathrm{ppb}$, and $300 \mathrm{ppb}$

103 of $\mathrm{Hg}^{2+}$, respectively. Spiked samples are used in method validation to identify matrix effects and

104 determine the recovery of the analytical method for a given analyte in a given matrix. 
105 The temperature ramp used for microwave-assisted digestion is shown in Table 1. Digestion 106 was achieved and no residues were observed.

\begin{tabular}{|c|c|c|c|}
\hline Step & Temp., $^{\circ} \mathbf{C}$ & Ramp, min & Hold, min \\
\hline 1 & 100 & 20 & 10 \\
\hline 2 & 180 & 20 & 10 \\
\hline 3 & Cool down & NA & 10 \\
\hline
\end{tabular}

Table 1 Temperature Ramp for Fish Muscle Tissue Microwave-Assisted Digestion.

107 After digestion, $1 \mathrm{~mL}$ of the acidic samples were diluted with $\mathrm{DI} \mathrm{H}_{2} \mathrm{O}$ to a final volume of 10

$108 \mathrm{~mL}($ Dilution factor $=10)$. Table 2 shows the most abundant and recommended $\mathrm{Hg}$ isotopes for 109 analysis and their potential interferences. $\mathbf{H g}^{\mathbf{2 0 0}}$ was the isotope used for quantification due to 110 lower potential interferences.

\begin{tabular}{|c|c|c|c|}
\hline \multirow{2}{*}{ Element } & Isotope (amu) & $\begin{array}{c}\text { Isotope } \\
\text { Abundance (\%) }\end{array}$ & $\begin{array}{c}\text { Potential } \\
\text { Interferences }\end{array}$ \\
\hline \multirow{2}{*}{$\mathrm{Hg}$} & 200 & 23 & $\mathrm{WO}^{+}$ \\
\cline { 2 - 4 } & 202 & 30 & $\mathrm{WO}^{+}$ \\
\hline
\end{tabular}

Table 2 Recommended Mercury Isotopes for Analysis and their Potential Interferences.

\section{Measurement Instrumentation}

112 Instrumental measurement was performed with an Agilent ICP-MS consisting of a 7800 ICP and

113 a quadrupole MS with an autosampler. The system has a mass range from 2-260 amu and detection

114 limits of $0.1 \mathrm{ppt}$ for ${ }^{209} \mathrm{Bi}$. It also includes a mass-flow controller for the nebulizer Argon and a 115 peristaltic pump for sample solutions. ICP-MS MassHunter software was used for analyte 116 quantification. The software allows correction for isobaric interferences and the application of IS 117 validation technique. The ICP-MS was set to measure in Helium mode, which reduces polyatomic 118 interferences, improves detection limits, and increases dynamic range. ${ }^{13,14}$ Isotopes ${ }^{199} \mathrm{Hg}$ through $119{ }^{202} \mathrm{Hg}$ were measured, but only ${ }^{200} \mathrm{Hg}$ was used for quantification as it shows lower interferences. 


\section{RESULTS}

121 Sockeye Salmon

122 In order to determine the total $\mathrm{Hg}$ concentration for Sockeye Salmon, only calibration points 1

123 through 11 - ranging from 0 to $1800 \mathrm{ppt}$ - were used (Figure 1). Sockeye Salmon showed the

124 lowest concentration of $\mathrm{Hg}$ and, therefore, the calibration curve was trimmed at low $\mathrm{Hg}$ levels to

125 provide more reliable results. No IS normalization was needed as indium showed great stability

126 during the measurement process. Good linearity was achieved with a correlation coefficient $\left(\mathrm{R}^{2}\right)$

127 of 0.9982 , which signifies high confidence in the correlation between the independent and

128 dependent variable. ${ }^{29}$ In addition, the statistical F-test was used to determine any outliers in the

129 calibration curve, as described by Andriamahenina et al. ${ }^{15}$ No outliers were detected using a $95 \%$

130 confidence interval. The detection limit was $91.4 \mathrm{ppt}$, which was calculated using the method

131 described by Skoog et al., where the average of 25 blank measurements is added to three times the

132 standard deviation of the blank measurements. ${ }^{16}$

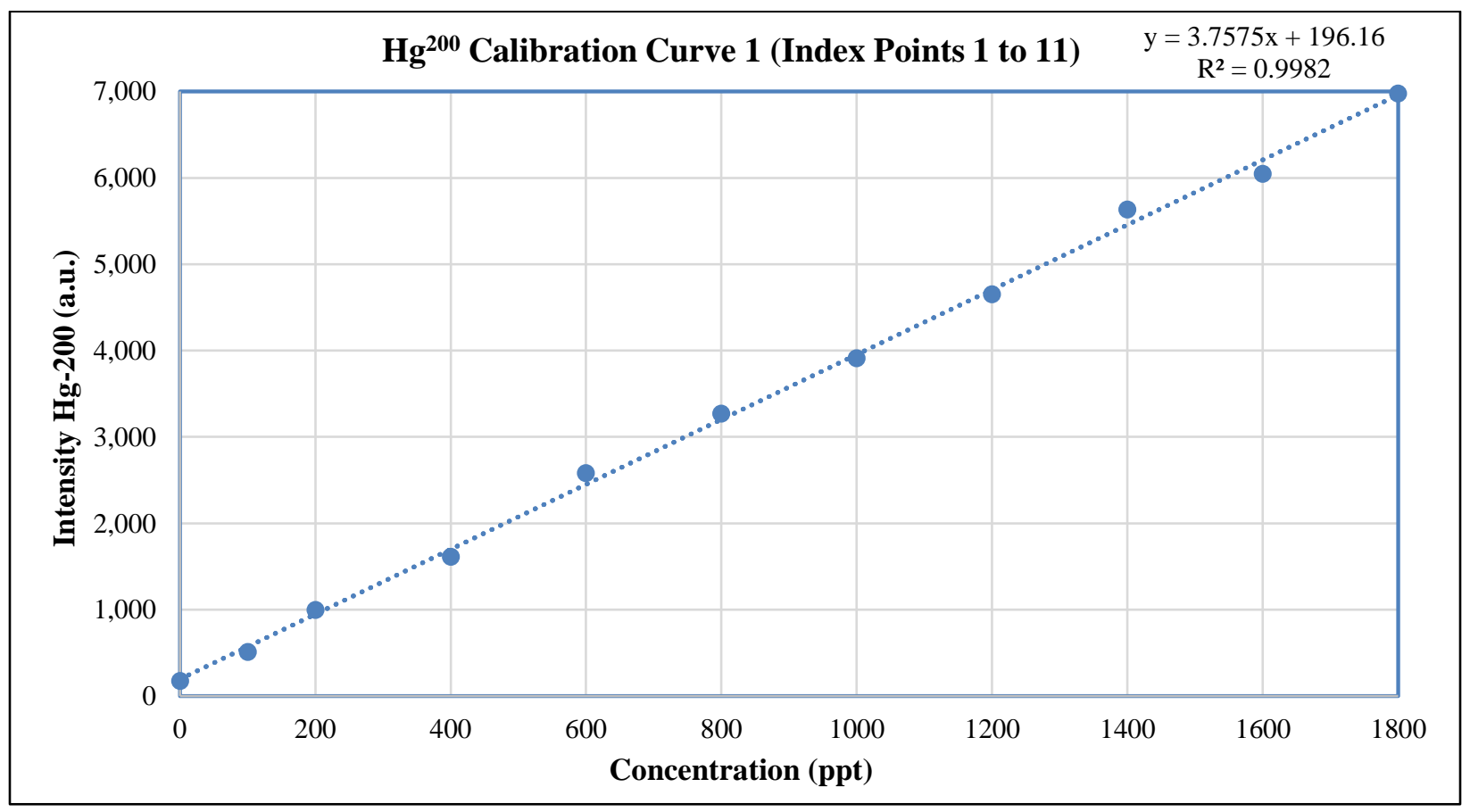

Figure 1 Calibration Curve 1 with Index Points 1 through 11. 
133 A method blank and three salmon fish samples were measured, one of which was spiked. Table

1343 shows the values obtained for the method blank and salmon samples. The concentration of the

135 sample was converted to represent the total $\mathrm{Hg}$ concentration in the edible portion. The average

136 total $\mathrm{Hg}$ concentration was $\mathbf{1 9 . 8} \pm \mathbf{2 . 9} \mathbf{p p b}$ wet $\mathbf{w t}$, and the concentration for S3-Spike was 31.3

137 ppb wet wt. Error analysis was performed by calculating the standard deviation in concentration

$138\left(\mathrm{~S}_{\mathrm{c}}\right)$, as described by Skoog et al., which was then transformed to account for the weight of each

139 sample. ${ }^{16}$ The percent recovery was $\mathbf{5 9 . 3 \%}$.

\begin{tabular}{|c|c|c|c|c|c|}
\hline Sample & Weight & $\begin{array}{c}\text { Concentration } \\
\text { Diluted (ppt) }\end{array}$ & $\begin{array}{l}\text { Concentration } \\
\text { Digested (ppt) }\end{array}$ & $\begin{array}{c}{ }^{200} \mathrm{Hg} / \text { gram } \\
\text { (ng/g or ppb) }\end{array}$ & $\begin{array}{c}\text { Error Analysis } \\
\text { (ng/g or ppb) }\end{array}$ \\
\hline $\begin{array}{l}\text { Method } \\
\text { Blank }\end{array}$ & NA & 54.4 & 544 & NA & NA \\
\hline S1 & 0.8111 & 160.9 & 1610 & 19.8 & \multirow{2}{*}{$19.8 \pm 2.92$} \\
\hline S2 & 0.8480 & 167.2 & 1672 & 19.7 & \\
\hline S3-Spike & 0.9033 & 282.6 & 2826 & 31.3 & 31.3 \\
\hline
\end{tabular}

Table 3 Salmon $\mathrm{Hg}^{2+}$ Concentration and Error Analysis.

140 Swordfish and Tuna

141 To determine the total $\mathrm{Hg}$ concentration for swordfish and tuna, calibration points 1 through 20

142 - ranging from 0 to $40,000 \mathrm{ppt}$ - were used. The $\mathrm{Hg}^{2+}$ internal spike concentration for swordfish

143 and tuna were $300 \mathrm{ppb}$ and $35 \mathrm{ppb}$ before dilution, respectively. Again, the F-test was used to

144 determine any outliers in the calibration curve based on a 95\% confidence interval, and no outliers

145 were detected. Good linearity is demonstrated in Figure 2, with a $\mathrm{R}^{2}$ value of 0.9999 . The limit of

146 detection was $91.4 \mathrm{ppt}$. 


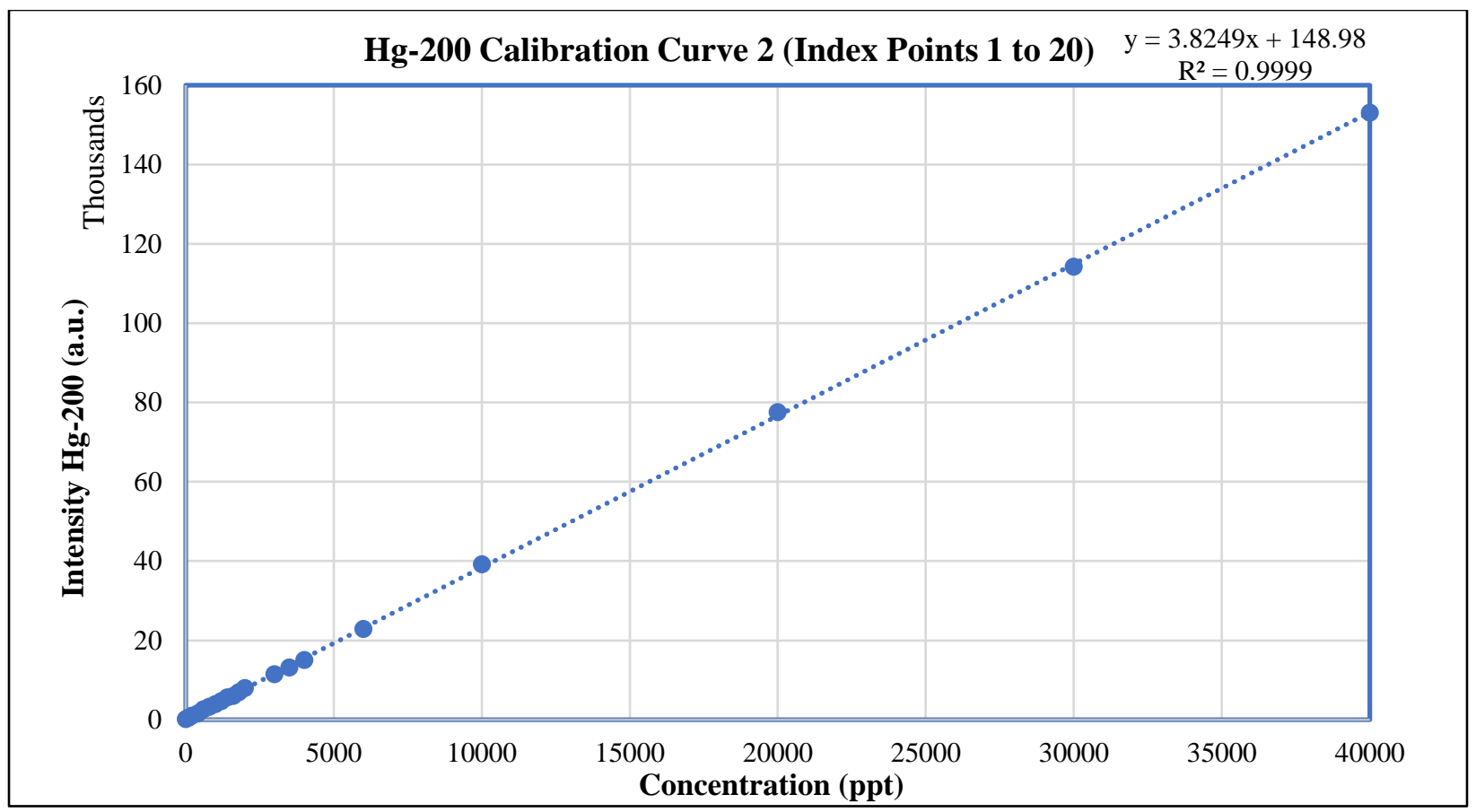

Figure 2 Calibration Curve 2 with Index Points 1 through 20.

147 In addition to a method blank, three samples of swordfish and three samples of tuna were 148 prepared, of which two were spiked. Table 4 demonstrates the concentration and error analysis for $149 \mathrm{Hg}^{2+}$ in the edible portion. For swordfish, the average concentration was $2.67 \pm \mathbf{0 . 0 1} \mathbf{p p m}$ wet wt, 150 with an S6-Spike concentration of $\mathbf{5 . 3 2} \mathbf{~ p p m}$ wet wt. The percent recovery was 81. 4\%. For tuna, 151 the average concentration was $\mathbf{3 8 0} \pm \mathbf{9} \mathbf{p p b}$ wet wt, with an S9-Spike concentration of $852 \mathbf{p p b}$ 152 wet wt. The percent recovery was $148.9 \%$.

\begin{tabular}{|c|c|c|c|c|c|c|}
\hline Species & Sample & Weight & $\begin{array}{c}\text { Concentration } \\
\text { Diluted (ppt) }\end{array}$ & $\begin{array}{l}\text { Concentration } \\
\text { Digested (ppt) }\end{array}$ & $\begin{array}{c}{ }^{200} \mathrm{Hg} / \mathrm{gram} \\
(\mu \mathrm{g} / \mathrm{g} \text { or } \mathrm{ppm})\end{array}$ & $\begin{array}{c}\text { Error Analysis } \\
(\mu \mathrm{g} / \mathrm{g} \text { or } \mathrm{ppm})\end{array}$ \\
\hline NA & $\begin{array}{c}\text { Method } \\
\text { Blank }\end{array}$ & NA & 54.4 & 544.04 & NA & NA \\
\hline \multirow{3}{*}{ Swordfish } & S4 & 0.9484 & 25012.5 & 250125 & 2.64 & \multirow{2}{*}{$2.67 \pm 0.00769$} \\
\hline & S5 & 0.9591 & 25858.9 & 258589 & 2.70 & \\
\hline & S6-Spike & 0.9370 & 49850.9 & 498509 & 5.32 & 5.32 \\
\hline \multirow{3}{*}{ Tuna } & S7 & 0.9042 & 3123.5 & 31235 & 0.35 & \multirow{2}{*}{$0.380 \pm 0.00853$} \\
\hline & S8 & 0.8341 & 3457.1 & 34571 & 0.41 & \\
\hline & S9-Spike & 0.9983 & 8501.1 & 85011 & 0.85 & 0.852 \\
\hline
\end{tabular}

Table 4 Swordfish and Tuna $\mathrm{Hg}^{2+}$ Concentration and Error Analysis. 


\section{DISCUSSION}

154 The present analytical method is validated for quantification of $\mathrm{Hg}$ in fish muscle samples. 155 Accuracy was demonstrated by calculating recoveries. For Sockeye Salmon (59\%) and for tuna $156(149 \%)$, recoveries were very close to, but did not lie within the ideal $70-130 \%$ range. Sufficient 157 recoveries were achieved for swordfish (81\%). In addition, a low limit of detections of $91.4 \mathrm{ppt}$ 158 was achieved and the method blank did not show significant $\mathrm{Hg}$ contamination. Good linearity 159 was demonstrated for the calibration curve $\left(\mathrm{R}^{2}=0.9999\right)$, and a quality control with a $6 \%$ error 160 confirmed precision of the method.

161 Results from this study are consistent with bioaccumulation effects and show that total $\mathrm{Hg}$ 162 concentration is dependent on the fish species and fish size. Mercury concentration in Sockeye 163 Salmon from Alaska (USA) was determined to be $20 \mathrm{ppb}$, significantly below the Food and Drug 164 Administration's (FDA) action level of 1 ppm (wet wt) in the edible portion. ${ }^{17}$ In the case of tuna 165 imported from Vietnam, $\mathrm{Hg}$ concentration was found to be $380 \mathrm{ppb}$ (wet wt), also significantly 166 below FDA's action level. In contrast, $\mathrm{Hg}$ concentration in swordfish imported from Indonesia 167 was estimated to be $2.7 \mathrm{ppm}$ (wet wt), which is close to three times FDA's action level and poses 168 a risk to human health. FDA's recorded mean concentration of swordfish from over 600 samples

169 is $0.995 \mathrm{ppm}$. A frequency distribution and a scatter plot of this data is provided in Figure 3 and

170 Figure 4, respectfully. ${ }^{18}$ Further analysis of imported swordfish samples should be conducted in 171 the future to determine if samples imported from Indonesia present an additional risk compared to 172 those from other regions, as our sample is more than three standard deviations away from the 173 mean. It is also important to note that the FDA level is less strict than the European Union's action 174 level of 0.5 ppm. $^{19}$ 


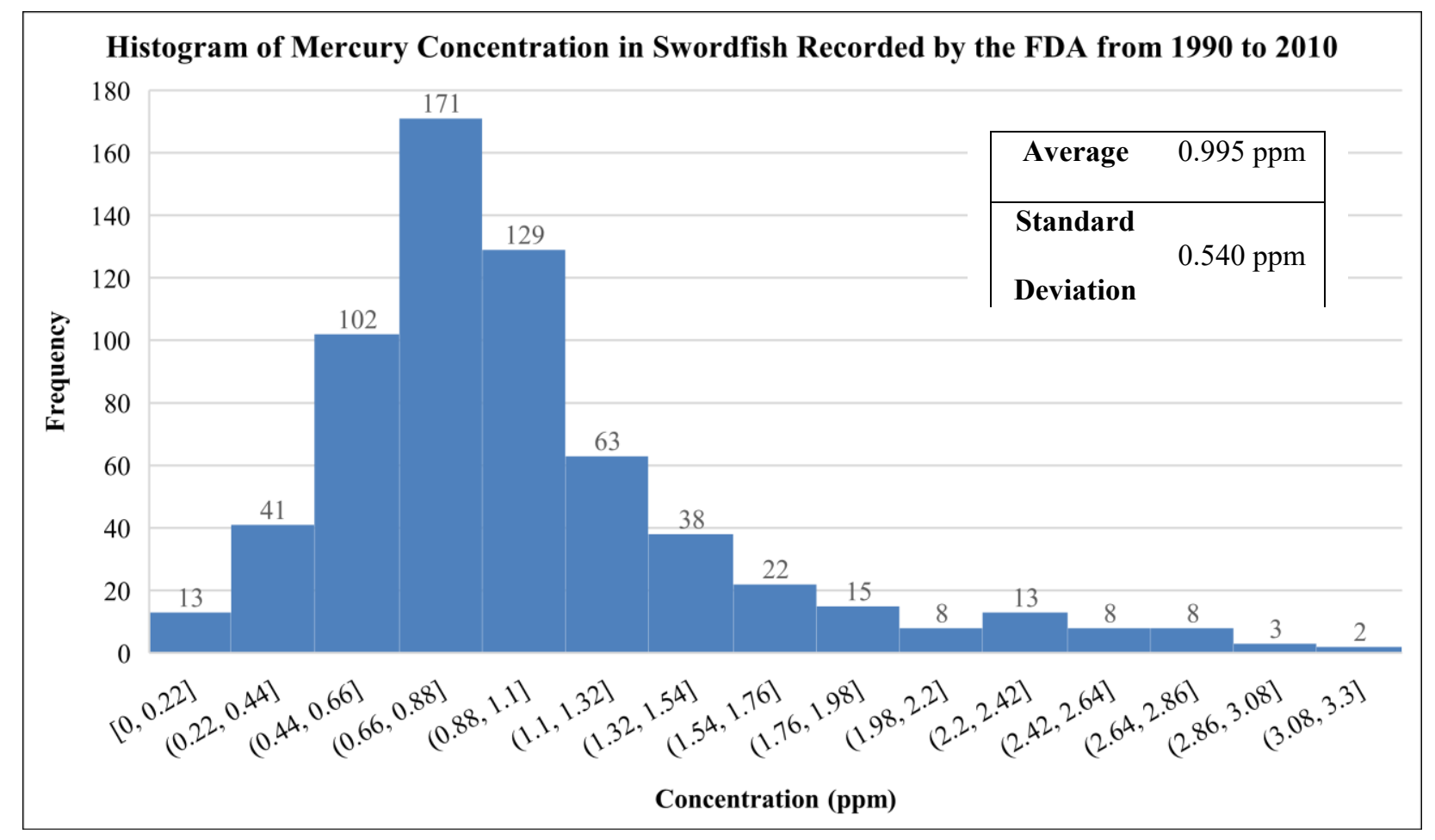

Figure 3 Frequency Distribution of Mercury Concentration in Swordfish Samples

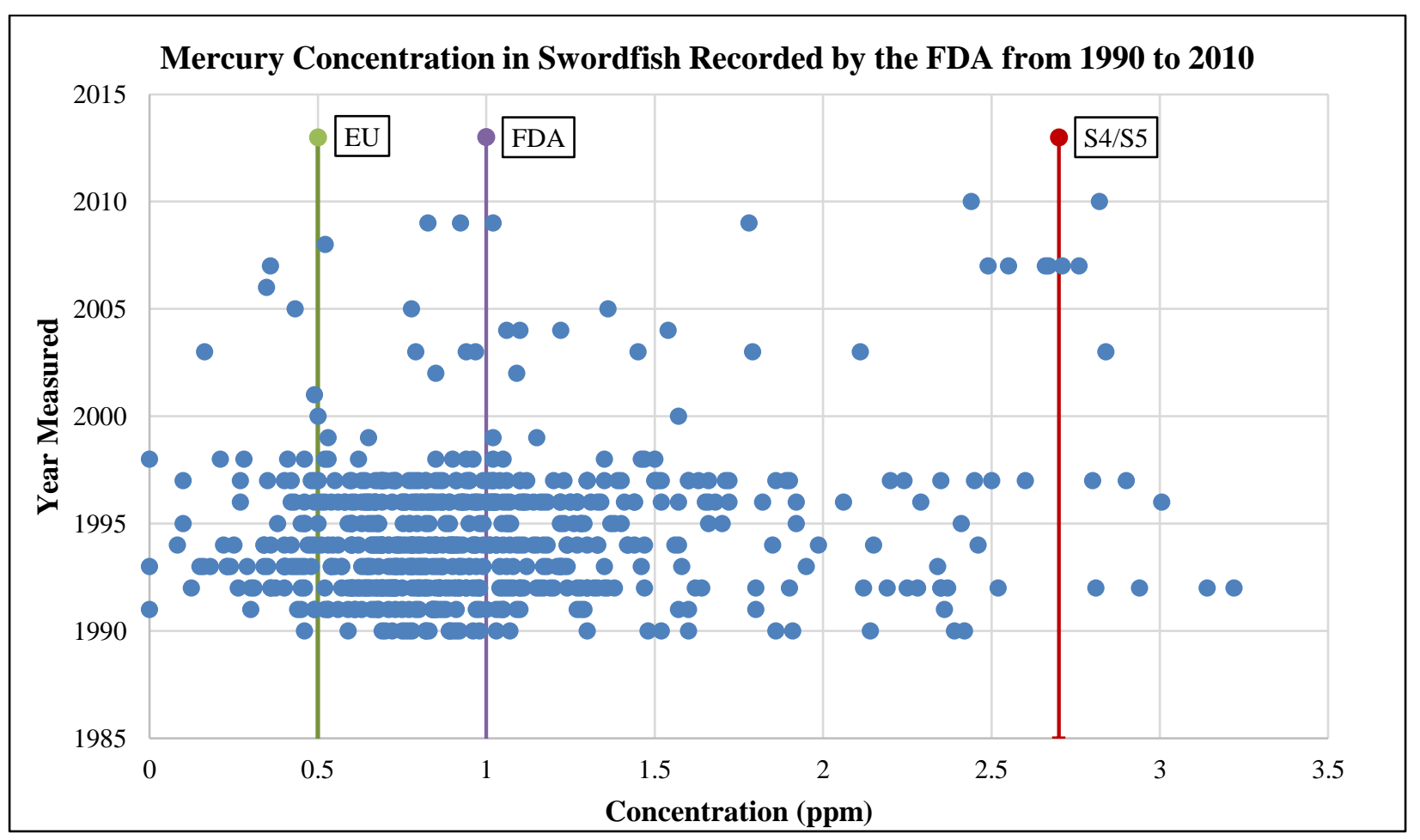

Figure 4 Scatter Plot of Year Measured and Concentration of Swordfish Samples 
175 Given that wild caught fish samples analyzed in the present study were purchased from a Harris

176 Teeter grocery store located in Washington, D.C., no information is available as to the size and

177 weight of the original fish, which is key to understanding bioaccumulation effects. However, there

178 is information on average size and weight of these species that is consistent with the results

179 obtained from this experiment. Sockeye Salmon, which showed the lowest Hg concentration, are

180 estimated to be 1.5 to 2.5 feet in length and 4 to 15 pounds $^{20}$, whereas swordfish, which showed

181 the highest $\mathrm{Hg}$ concentration, are predatory fish that commonly weigh 200 on average, but can

182 reach to 14 feet in length and weigh almost 1,200 pounds. ${ }^{21}$ Although fully mature adult tuna

183 species, like the Atlantic and Southern bluefin tuna, average 6.5 to 8 feet long and weigh around

184550 pounds, these larger species are critically endangered. ${ }^{22,23}$ Since no specifications were

185 provided in the grocery store, it is most likely that the tuna sample analyzed belongs to a smaller

186 more commonly sold species, thus explaining significantly lower Hg concentrations in tuna

187 compared to swordfish.

188 In terms of how the region of origin might affect $\mathrm{Hg}$ concentration, it is impossible to draw clear

189 conclusions as no comparison has been conducted between sample species from different

190 locations. Thus, it remains unclear whether the region of origin influences Hg concentration. Given

191 that fish imported from certain countries or regions might pose additional risk than others, future

192 experiments will be geared towards analyzing same fish species, mainly swordfish, from different

193 locations around the globe. The United States Environmental Protection Agency (EPA) publishes

194 the National Listing of Fish Advisories (NFLA), which uses geographic information systems (GIS)

195 to provide a historical listing of fish advisories in the U.S. from 1974 to $2011 .{ }^{24}$ Individual states

196 usually provide residents with current local advisories, which is often also provided in a GIS

197 format. Currently, there are no listings for fish advisories for fish imported into the U.S. and using 
198 GIS for $\mathrm{Hg}$ mapping for imported fish would provide valuable data to those involved in risk 199 communication and public health protection and would help consumers make informed decisions 200 on fish consumption.

201 Results showed that from the three wild caught fish species analyzed, only swordfish is likely to 202 pose a risk to public health. While the FDA and EPA advise against the consumption of swordfish

203 for pregnant women and children, it is still allowed to be sold in the U.S. ${ }^{25}$ Thus, further research 204 and environmental monitoring will need to be conducted in the future to ensure that the average $205 \mathrm{Hg}$ concentration of imported swordfish falls below current action levels. In addition, working 206 with local fish market to ensure fish size would enable estimation of bioaccumulation effects in 207 different species.

\section{ACKNOWLEDGEMENTS}

209 The authors are grateful for Dr. Dejun Chen's professional assistance and expertise in analytical 210 methodology and instrumentation. This research was supported by the Environmental Metrology 211 and Policy Graduate Degree Program at Georgetown University, Washington D.C. 


\section{REFERENCES}

(1) Kidd, K.; Clayden, M.; Jardine, T. Bioaccumulation and Biomagnification of Mercury through Food Webs. In Environmental Chemistry and Toxicology of Mercury; John Wiley and Sons, 2011; pp 453-499. https://doi.org/10.1002/9781118146644.ch14.

(2) Storelli, M. M.; Barone, G.; Piscitelli, G.; Marcotrigiano, G. O. Mercury in Fish: Concentration vs . Fish Size and Estimates of Mercury Intake. Food Addit. Contam. 2010, 24 (12), 1353-1357. https://doi.org/10.1080/02652030701387197.

(3) Deckere, E. A. M. de. Health Aspects of Fish and N-3 Polyunsaturated Fatty Acids from Plant and Marine Origin. Nutr. Heal. 2001, 195-206. https://doi.org/10.1007/978-1-59259226-5_13.

(4) Billman, G. E.; Kang, J. X.; Leaf, A. Prevention of Sudden Cardiac Death by Dietary Pure œ-3 Polyunsaturated Fatty Acids in Dogs. Circulation 1999, 99 (18), 2452-2457. https://doi.org/10.1161/01.CIR.99.18.2452.

(5) Rosenberg, I. H. Fish — Food to Calm the Heart. N. Engl. J. Med. 2009, 346 (15), $1102-$ 1103. https://doi.org/10.1056/NEJM200204113461502.

(6) Kris-Etherton, P. M.; Harris, W. S.; Appel, L. J. Omega-3 Fatty Acids and Cardiovascular Disease: New Recommendations from the American Heart Association. Arterioscler. Thromb. Vasc. Biol. 2003, $23 \quad$ (2), 151-152. https://doi.org/10.1161/01.ATV.0000057393.97337.AE.

(7) United Kingdom National Health Service. Fish and Shellfish|United Kingdom National Health Service https://www.nhs.uk/live-well/eat-well/fish-and-shellfish-nutrition/.

(8) Harada, M. Minamata Disease: Methylmercury Poisoning in Japan Caused by Environmental Pollution. Crit. Rev. Toxicol. 2008, 25 (1), 1-24. https://doi.org/10.3109/10408449509089885.

(9) Briscoe, M.; Sullivan, D.; Alewijn, M.; Austad, J.; Boison, J.; Christiansen, S.; Cook, J. M.; 
De Vries, J.; Indyk, H.; Joseph, G.; Konings, E.; Krynitsky, A.; Phillips, T.; Popping, B.; Reddy, M.; Wong, J. Determination of Heavy Metals in Food by Inductively Coupled Plasma-Mass Spectrometry: First Action 2015.01. J. AOAC Int. 2015, 98 (4), 1113-1120. https://doi.org/10.5740/jaoac.int.2015.01.

(10) U.S. EPA. Method 6020B (SW-846): Inductively Coupled Plasma-Mass Spectrometry Revision 2; Washington DC, 2014.

(11) Sanborn, J.; Brodberg, R. Evaluation of Bioaccumulation Factors and Translators for Methylmercury. 2006.

(12) Allibone, J.; Fatemian, E.; Walker, P. J. Determination of Mercury in Potable Water by ICPMS Using Gold as a Stabilising Agent. J. Anal. At. Spectrom. 1999, 14 (2), 235-239. https://doi.org/10.1039/a806193i.

(13) Hintelmann, H.; Ogrinc, N. Determination of Stable Mercury Isotopes by ICP/MS and Their Application in Environmental Studies. 2003.

(14) Yamanaka, K.; Wilbur, S. Introduction Investigations into the Use of Helium Collision Mode and Aerosol Dilution for Ultra-Trace Analysis of Metals in Mineral Reference Materials. Agil. Technol.

(15) Andriamahenina, N. N.; Rasoazanany, E. O.; Ravoson, H. N.; Rakotozafy, L. V.; Harinoely, M.; Andraimbololona, R.; Edmond, R. Dealing with Outlier in Linear Calibration Curves: A Case Study of Graphite Furnace Atomic Absorption Spectrometry.

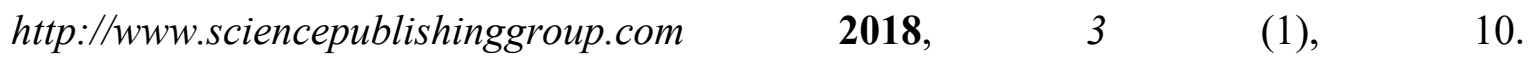
https://doi.org/10.11648/J.WJAC.20180301.12.

(16) Crouch, S.; Skoog, D.; Holler, F. J. Principles of Instrumental Analysis Seventh Edition. Pure Appl. Chem. 2016, 88 (3), 265-291.

(17) CPG Sec. 540.600 Fish, Shellfish, Crustaceans and other Aquatic Animals - Fresh, Frozen or Processed - Methyl Mercury | FDA https://www.fda.gov/regulatory-information/searchfda-guidance-documents/cpg-sec-540600-fish-shellfish-crustaceans-and-other-aquaticanimals-fresh-frozen-or-processed-methyl. 
(18) Mercury Levels in Commercial Fish and Shellfish (1990-2012) | FDA https://www.fda.gov/food/metals-and-your-food/mercury-levels-commercial-fish-andshellfish-1990-2012.

(19) European Union. Commission Regulation (EC) No 1881/2006 Setting Maximum Levels for Certain Contaminants in Foodstuffs. Off. J. Eur. Union 2006.

(20) Sockeye Salmon | NOAA Fisheries https://www.fisheries.noaa.gov/species/sockeyesalmon.

(21) North Pacific Swordfish | NOAA Fisheries https://www.fisheries.noaa.gov/species/northpacific-swordfish.

(22) Southern Bluefin Tuna | Australian Fisheries Management Authority https://www.afma.gov.au/fisheries-management/species/southern-bluefin-tuna.

(23) Atlantic Bluefin Tuna National Geographic https://www.nationalgeographic.com/animals/fish/facts/atlantic-bluefin-tuna.

(24) National Listing of Fish Advisories Technical Maps | EPA https://www.epa.gov/waterdata/national-listing-fish-advisories-technical-maps.

(25) EPA-FDA Advice about Eating Fish and Shellfish| EPA https://www.epa.gov/fishtech/epa-fda-advice-about-eating-fish-and-shellfish. 